\title{
Performance Comparison for NDWCT Using Trickle Fill at Different Weather Conditions
}

\author{
Qasim Saleh Mahdi $^{\# 1}$, Muwafaq Rahi Al- Hachami ${ }^{* 2}$ \\ 1. Professor, Mechanical Engineering Dept., Al-Mustansiriyah University, Iraq, \\ 2. PhD Student, Mechanical Engineering Dept., Al-Mustansiriyah University, Iraq,
}

\begin{abstract}
A prototype design has been built to simulate natural draft wet cooling tower based on geometrical, dynamic and thermodynamic similarity. Experimental tests were done in summer (hot and dry) and at winter (cold and wet) weather according to Iraqi weather using $(10) \mathrm{cm}$ trickle fill. The mass flow rate of water has changed from $(0.8$ to 2.4$) \mathrm{gpm}$, and cross wind fixed at zero $(\mathrm{m} / \mathrm{s})$. The obtained results clarify that tower range, cooling capacity, and air temperature change, are higher at winter than them at summer where relative humidity change, enthalpy change, and $\dot{m}_{w} / \dot{m}_{a}$ show higher values at summer than them at winter. It is found that water consumption in winter is more than it in summer in spite of the more humidity in outside weather at winter.
\end{abstract}

Keywords — Cooling Tower, Trickle Fill, Hot Weather, Natural Draft, Iraqi Weather.

\section{INTRODUCTION}

(NDWCT) is widely used with big industrial processes specially power plants. Because of the high cost required to build NDWCT, economically, it has to be used with long life projects and has to operate effectively for 365 day/year. NDWCT used to discharge excess heat to environment so some critical balance lead the relation between wet cooling tower and environment. Hot and wet weather is the worse conditions in relation between weather and wet cooling tower where cold and dry weather represent the best situation in this relation. NDWCT achieved its goal by dissipate heat to environment from high temperature water which represents load through spraying that water from nozzles over packing fill then to storage tank under tower to collect cold water which is circulated again to load. This operation achieved by three cooling zones inside tower namely spray zone, packing (fill) zone, and rain zone. Packing or fill zone is the main zone and it is more effective. Main objective of fill is to offer big surface area and so increase contact surface between water and air and to decrease falling speed for water drops so more time is available. Trickle fill represent a combination between film and splash fill because it offer both thin film layer of water and breaking water into small drops.

During hot weather, NDWCT is less effective because of the low draft force which can draft air inside cooling tower, so it is widely available in regions of cold weather along all days in the year. Any plan to use NDWCT in hot areas has to take care about the air relative humidity or going to use hybrid cooling tower where the use of fan to assist draft is possible.
Iraqi weather is so hot at summer with main feature for NDWCT which is the dryness of air along all hot season. Due to Iraqi weather, worse conditions are at summer season (hot and dry), where climate changed to be cold and wet at winter. Main different between both cases is the amount of heat transfer and mass transfer (sensible and latent heat transfer). High mass transfer, less heat transfer at summer, reverse case is noted at winter.

\section{BACKGROUND}

Most of researchers focused on studying cooling towers at cold weather where it is more applicable. The researches divided mainly into studying the internal parameters inside tower and studying the environment effects on towers. Kloppers and Kröger [1,2], have focused on studying internal parts and parameters to find empirical correlations that figure out fill loss coefficient data and showed the effect of the Lewis factor, or Lewis relation, on the performance prediction of natural draft and mechanical draft wet-cooling towers. Kloppers and Kröger [3], studied the nocturnal temperature inversions and their detrimental effect on the performance of natural draft wet cooling towers. Studying the effects of the temperature inversion, the height of the inversion profile and the height from which air is drawn into the cooling tower, on the performance of cooling towers. Qureshi and Zubair [4], showed that a significant portion of the total heat rejected is occurred in the spray and rain zones and studied all zones decrease error in heat rejection calculations from $6.5 \%$ to $2.65 \%$. Zhai and S. Fu [5], focused on the wind effect on cooling tower, showed that wind-break walls placed at the lateral sides of cooling towers perpendicular to the cross-wind is a straightforward and effective method, and it can recover about $50 \%$ of the reduced cooling capacity. Gao et al. [6], founded experimentally that temperature difference and effectiveness are influenced by the cross-wind, and they may decrease mostly by $(6 \%$ and $5 \%)$, respectively. When the critical Froude number is less than $(0.174)$, and that equivalent to wind velocity of $0.45(\mathrm{~m} / \mathrm{s})$, temperature difference and effectiveness are decreased with the increasing of cross-wind velocity. However, when it is greater than $(0.174)$, they increase with increasing cross-wind velocity. Lemouari et al., [7], an experimental analysis of simultaneous heat and mass transfer phenomena between water and air by direct contact in a packed cooling tower has been studied. The main object is to investigate the effect of the air and water 
flow rates on the global heat and mass transfer coefficient and also the evaporation rate of water into the air stream using different inlet water temperatures. Ghassem Heidarinejada et al., [8], developed models of the three zones (spray, packing, and rain) of tower and validated against experimental data. For the case study under consideration, the error in calculation of the tower volume is $1.5 \%$ when the spray and rain zones are neglected. This error is reduced to $1.1 \%$ and $0.25 \%$ as the spray and rain zones are incorporated in the model, respectively. The effect of Lewis factor on the performance prediction of wet-cooling towers is investigated using Bosnjakovic equation. Lemouari and Boumaza [9], have approved experimentally that heat rejected by the cooling tower increases with the increasing of the air and water mass flow rates. Al-Waked [10], studied the thermal performance of two adjacent NDWCTs within PPS. The Numerical investigation uses (FLUENT) as a CFD code. . Wang et al [11], monitored and experimented the thermal performance of a natural-draft wet cooling tower model with inlet airflow guiding channels under crosswinds conditions. In the present work, (10) $\mathrm{cm}$ thickness of trickle fill type is studied with (2) $\mathrm{mm}$ nozzles and (Twin) fixed at $\left(50{ }^{\circ} \mathrm{C}\right)$. The effect of cross wind is included. The key point of this study is to compare different parameters of NDWCT at (hot and dry) weather with (cold and wet) weather. Navid Bozorgan and Nariman Bozorgan, [12], analyzed the performance of a counter flow wet cooling towers to improve the function of this tower and its effect on the related units. Studying energy and exergy of this cooling tower and analyzing both simultaneously. As a result, heat and mass transfer between ambient air and hot water, exergy and second-law efficiency in this cooling tower was evaluated in order to analyze its heat transfer performance. Xiaoni et al., [13], carried out energy and exergy analysis on a shower cooling tower based on mathematical modeling and simulation results. The method was validated using experimental data.

\section{EXPERIMENTAL WORK}

Rig is designed in simulations according to reference tower, located at Mt. Piper Power Station - Delta Electricity in Australia, is designed by Hamon-Sobelco LTD. Original tower height is (131) $\mathrm{m}$ and the fill base diameter is (98) $\mathrm{m}$. This tower has been used as reference tower for many investigations before as like those mentioned by [14, 15, and 16]. According to similarity theory and to simulate cooling tower, the geometry proportion of prototype tower is $1: 100$. The dimensions of the cooling tower are $(58 \mathrm{~cm} \times 98 \mathrm{~cm} \times$ $131 \mathrm{~cm}$ ) (top outlet diameter $\times$ bottom diameter $\times$ height). Dynamic and thermodynamic similarity guide air velocity into Reynolds number (Re) or Froude number (Fr). If following Reynolds number, air velocity will vary inversely with model scale which make air velocity in prototype higher than it at real tower so similarity should follow Froude number in which air velocity vary with square root of model scale. Experiment thermal state showed that the velocity has to achieve $\Delta \mathrm{Fr}$ for both the prototype and the model $[6,17]$, where:

$\Delta F r=\left(v_{\text {out }} / \sqrt{\frac{\Delta \rho}{\rho_{i}} g L}\right)_{P}=\left(v_{\text {out }} / \sqrt{\frac{\Delta \rho}{\rho_{i}} g L}\right)_{M}$

vout $=$ wind velocity at outlet $(\mathrm{m} / \mathrm{s})$

$\Delta \rho=$ density difference $(\mathrm{kg} / \mathrm{m} 3)$

$\rho \mathrm{i}=$ inlet density $(\mathrm{kg} / \mathrm{m} 3)$

$\mathrm{g}=$ gravity $(9.81 \mathrm{~kg} / \mathrm{m} 2 \mathrm{~s})$

$\mathrm{P}=$ denotes for prototype

$\mathrm{M}=$ denotes for model

Hyperbolic tower is built in real dimensions according to the following equations [13]:

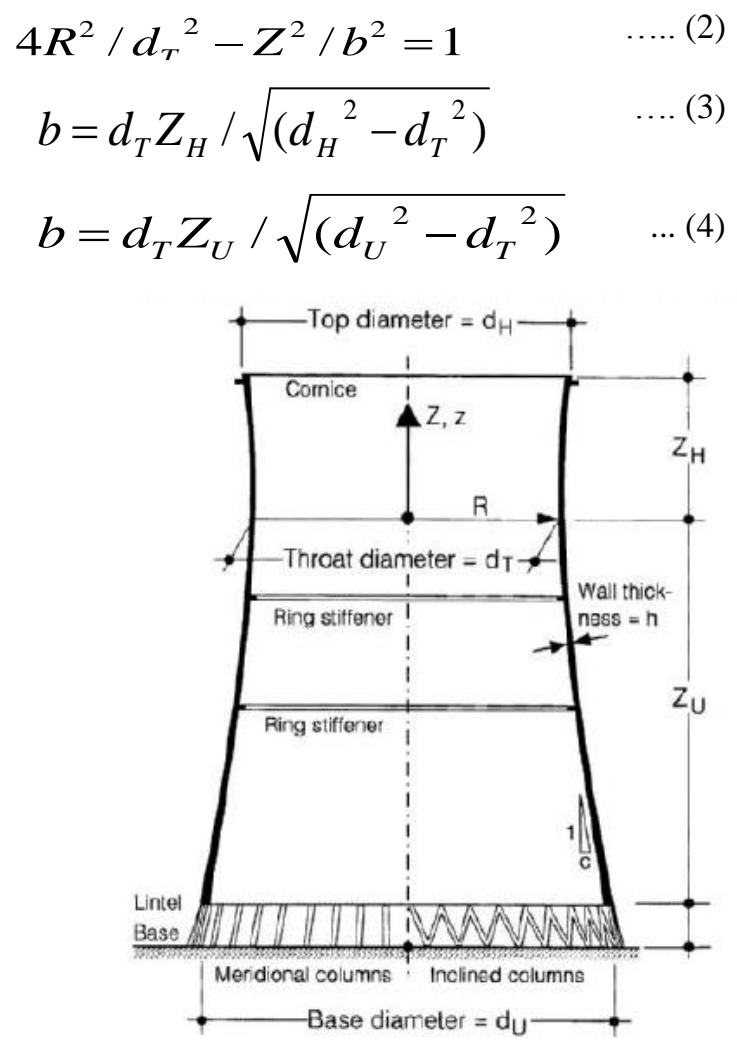

Fig.1 Tower shell design, [18].

Where:

$\mathrm{d}_{\mathrm{H}}$ top diameter $(58.17 \mathrm{~m})$

$\mathrm{d}_{\mathrm{T}}$ throat diameter $(53.5 \mathrm{~m})$

$\mathrm{d}_{\mathrm{U}}$ base diameter $(98 \mathrm{~m})$

$\mathrm{Z}_{\mathrm{U}}$ height from base to throat $(\mathrm{m})$

$\mathrm{Z}_{\mathrm{H}}$ height from throat to top $(\mathrm{m})$

$\mathrm{R}$ radius at any height $\mathrm{Z} \quad(\mathrm{m})$

Hot water is used to simulate load, its temperature controlled at $(50){ }^{\circ} \mathrm{C}$ by using two electrical heaters. Water flow rate is change as $(0.8,1,1.2,1.6,2$, and 2.4$)$ gallon per minute. 
Nozzles with diameter of (2) $\mathrm{mm}$ are used in this research where trickle fills with (10) $\mathrm{cm}$ is studied.

The measurements included measuring dry bulb temperature and relative humidity for air at both entrance and exit of tower, water temperature at inlet and outlet, air velocity at outlet, water mass flow rate, and pressure drop along tower shell. Figure (2) shows the main parts of rig.

Trickle fill is available in many designs like: cylindrical, splash or honey cells design, figure (3). For this work, trickle fill is simulated in cylindrical shape as shown in figure (3-b) using polyethylene grid with square holes of $(1 \times 1) \mathrm{cm}$, as shown in figure (4).

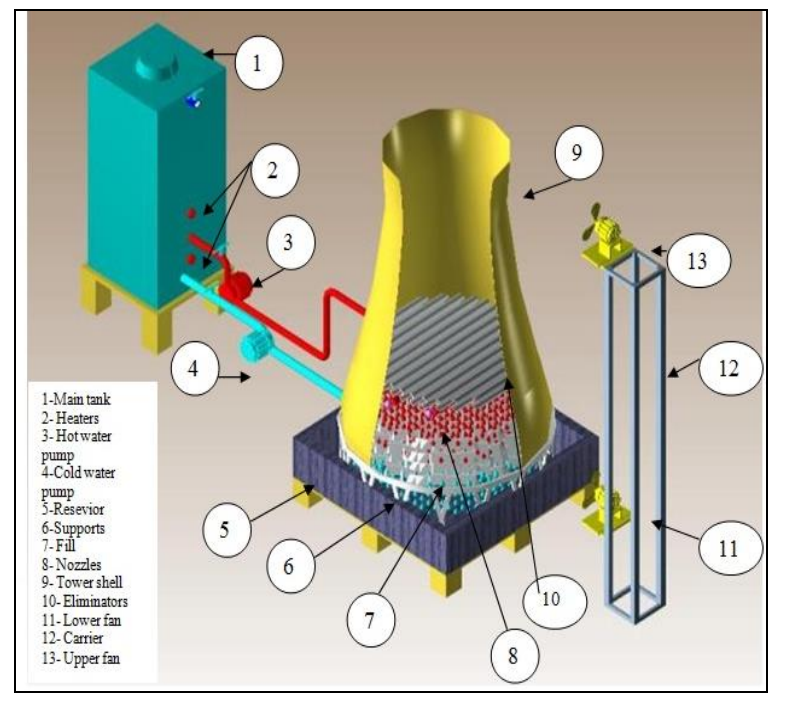

Fig.2 Rig design.

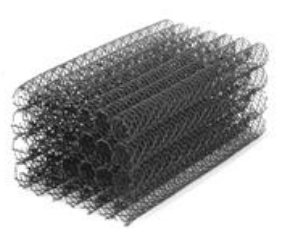

(a)

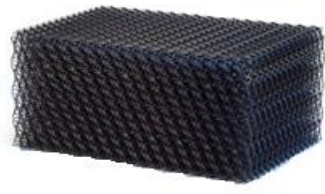

(c)

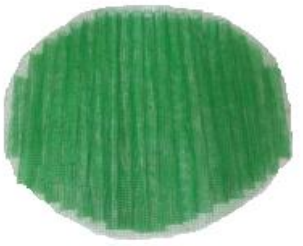

(b)

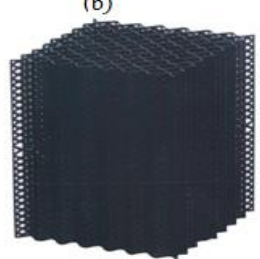

(d)
Fig.3 Trickle fill different designs.

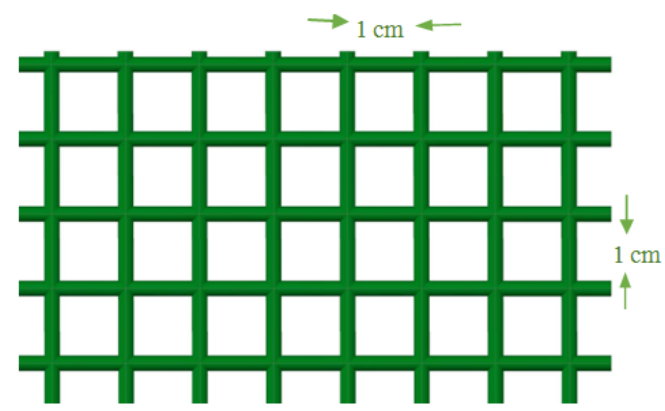

Fig.4 Polyethylene net used to simulate trickle fill

\section{DISCUSSIONS}

The behavior of air drafted inside tower can be summarized at psychometric chart as shown in figure (5). Node (A) and (D) represent the conditions of (cold and wet), (hot and dry) weathers respectively where node (B) represents air at outlet for both cases. Comparison tower behavior at two different weather conditions can be led from following points.

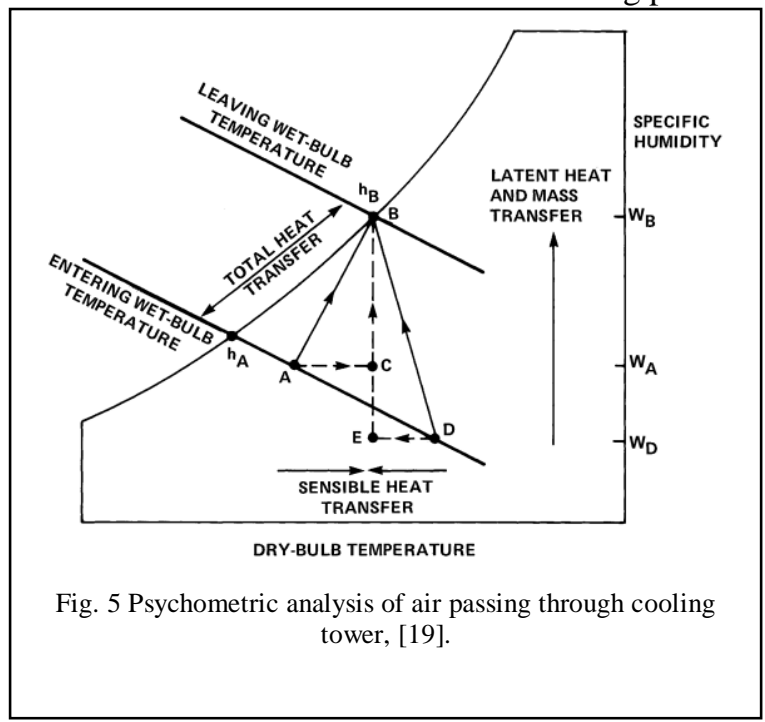

1. Humidity change at winter less than it at summer. Because of the higher humidity of inlet air at winter than it summer, humidity change will be less at winter as shown in figure (5). Where, the end point (B) depends on tower performance, points (A) and (D) depends on environments. Figure (6) showed that maximum change in relative humidity can reach up to $(60 \%)$ at summer which cannot happen at winter where point (A) having relative humidity with range from $(53 \%)$ to $(62 \%)$ that means maximum humidity change inside tower will not be more than (47\%) at winter according to any other conditions. Maximum humidity change recorded is $(45 \%)$ at winter. The average changes of relative humidity are $(54.57 \%)$ and $(37.13 \%)$ at summer and winter respectively.

2. Dry bulb temperature change is higher at winter and can be in negative value at summer. The temperature of cold air at winter will increase according to heat transfer with hot water inside cooling tower at interface area. At summer, inlet 
air temperature is already high and may decrease because of the big change in humidity due to high mass transfer. Change in air temperature inside tower is shown in figure (7).

The average temperature increase is (1.4) and (7.85) ${ }^{\circ} \mathrm{C}$ at summer and winter respectively.

3. Heat and mass transfer effected by increasing air enthalpy. Change in enthalpy can be higher at winter or summer depends on the total energy added to air. It is clear that mass transfer plays the main role at summer while heat transfer plays that role at winter. Figure (8) shows that air enthalpy change is mostly higher at summer.

Experimentally, results show that average air enthalpy change at summer $(42.45) \mathrm{kJ} / \mathrm{kg}$ higher than it at winter (35.67) $\mathrm{kJ} / \mathrm{kg}$.

4. Change in air density through the shell is the main reason behind buoyancy force. Increasing density difference, increases drafting force and so decrease water to air mass flow rate ratio $\dot{m}_{w} / \dot{m}_{a}$. This ratio represent master key for tower performance, the less is the best.

Big difference is noticed at figure (9) where less ratio at winter with average of (0.6) and average of (1.08) at summer. While water mass flow rate is controlled, the less water to air mass flow ratio means higher air mass flow rate and so more heat rejected to environment.

Total heat rejection comes from multiplying air enthalpy change by air mass flow rate. Heat rejected to the environment is higher at winter as shown in figure (10). Average heat lifted with air is (5.59) $\mathrm{kW}$ at winter and (3.78) $\mathrm{kW}$ at summer.

Heat rejected by air should be equal to the cooling capacity which is the product of water mass flow rate $\dot{m}_{w}$ by tower range $(R)$, range is the different in water temperature at inlet and outlet.

For a system operating in a steady state, range is the same as the water temperature rise through the load, provided mass flow rate through the cooling tower and heat exchanger are the same. Accordingly, the range is determined by the heat load and water flow rate which mean that range is not a measure for tower performance in real situation. Average range at summer $(9.117){ }^{\circ} \mathrm{C}$ where it is $(9.817){ }^{\circ} \mathrm{C}$ at winter.

$$
\text { Range }=\left(T_{\text {win }}-T_{\text {wout }}\right)
$$

The deference between water outlet and wet bulb temperature for air inlet is called tower approach. Tower approach is a function of cooling tower capability. For a given heat load, flow rate, and air condition, larger cooling tower produces a closer approach (colder outlet water). The best performance is the lowest approach and the highest range. Average approach at summer $(24.38)^{\circ} \mathrm{C}$ where it is (29.58) ${ }^{\circ} \mathrm{C}$ at winter.

$$
\text { Approach }=\left(T_{\text {wout }}-T_{\text {ain }}\right)
$$

Figures (11, and 12) show that both range and approach are higher at winter than same at summer which will lead to calculate tower effectiveness which is the ratio of range due to (range + approach).

Effectiven ess $=\frac{\text { Range }}{\text { Range }+ \text { Approch }}=\frac{\left(T_{\text {win }}-T_{\text {wout }}\right)}{\left(T_{\text {win }}-T_{\text {ain }}\right)}$

The critical relation which made both range and approach are higher at winter made effectiveness higher at summer as shown in figure (13). Average effectiveness at summer $(27.2 \%)$ where it is $(24.9 \%)$ at winter.

Tower capacity represents the total heat lost from water inside cooling tower; it is calculated as [14]:

$$
\text { Tower capacity }(\mathrm{kW})=\frac{c p_{w}}{1000} \times \dot{m}_{w} \times\left\{T_{\text {in }}-\left(1-\Delta \dot{m}_{w}\right) \times T_{\text {out }}\right\}
$$

Where $\Delta \dot{m}_{w}$ is water consumed by evaporation which calculated by:

$$
\Delta \dot{\circ}_{w}=\rho v_{o u t} \frac{\left(\Pi d^{2}\right)}{4}\left(W_{o u t}-W_{i n}\right)
$$

$\mathrm{W}$ is vapor content in air $(\mathrm{kgv} / \mathrm{kga})$ and (d) is top diameter.

Tower capacity at winter higher than it at summer while they increased so closely by increasing water mass flow rate, figure (14).

Heat rejected by air showed same behavior also where it is higher at winter and increases with water mass flow rate increasing. Water consumption show higher values at winter because of the lower $\dot{m}_{w} / \dot{m}_{a}$ in spite of the higher change in relative humidity at summer, figure (15).

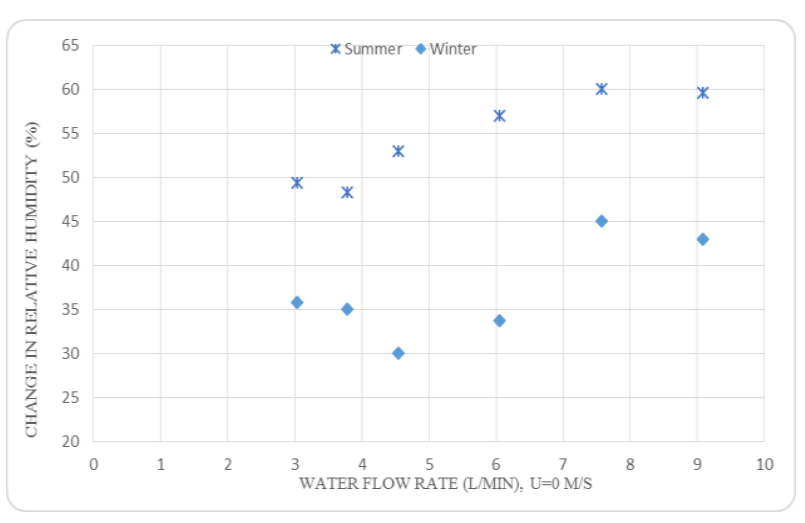

Fig.6 Humidity change at summer and winter. 
International Journal of Engineering Trends and Technology (IJETT) - Volume 19 Number 3 - Jan 2015

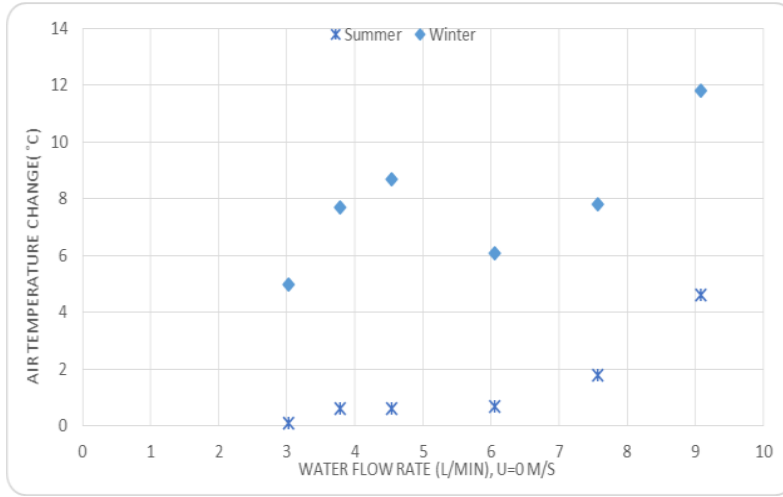

Fig.7 Air temperature change at summer and winter.

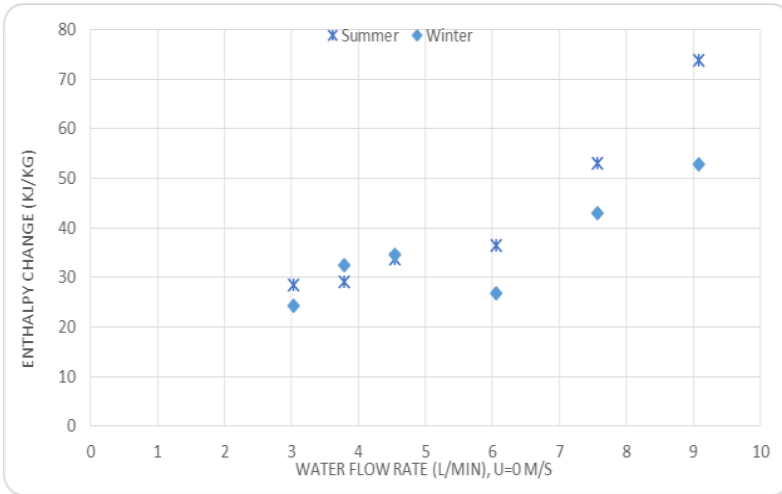

Fig.8 Air enthalpy change at summer and winter.

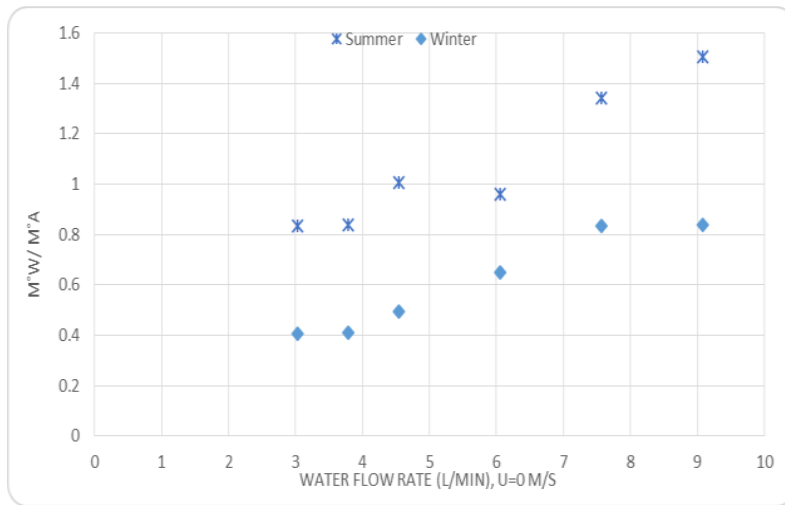

Fig.9 Water to air mass flow rate ratio at summer and winter.

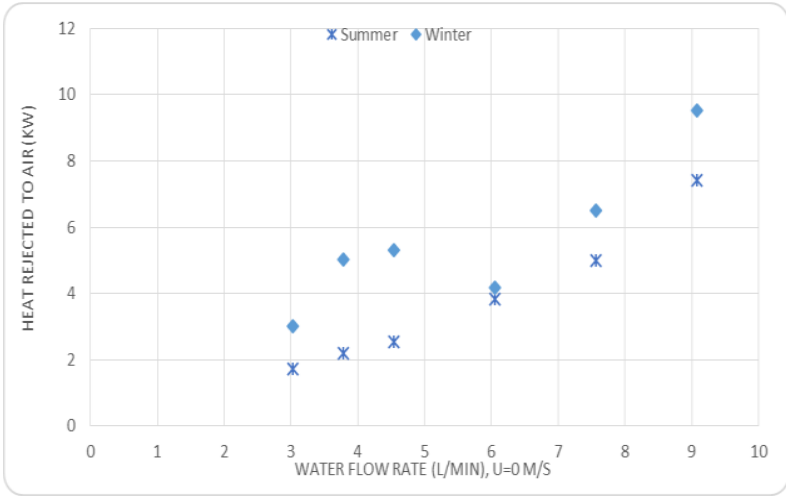

Fig.10 Heat rejected to at summer and winter.

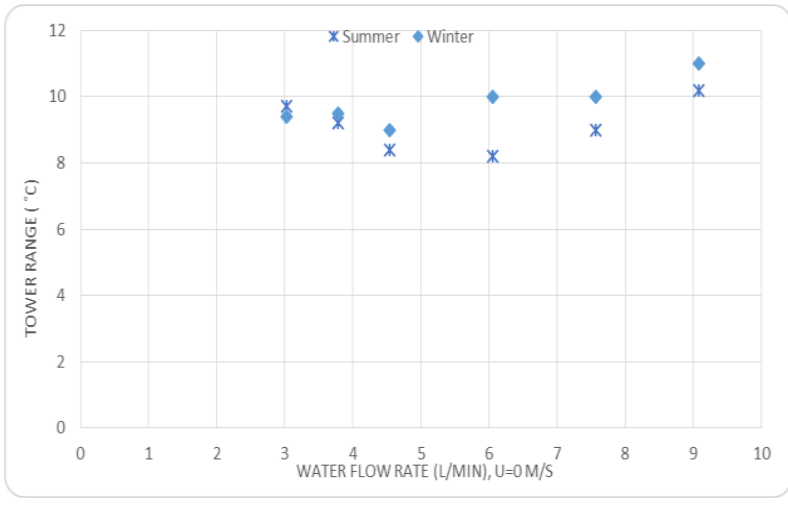

Fig.11 Tower range at summer and winter.

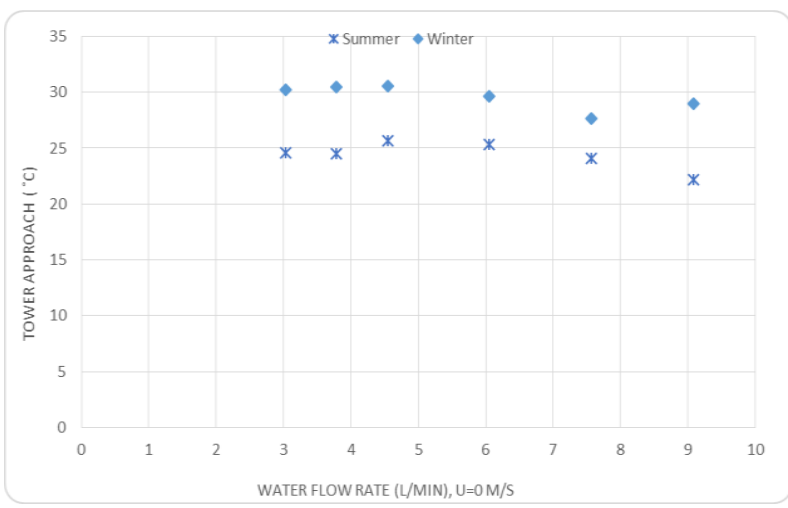

Fig.12 Tower approach at summer and winter.

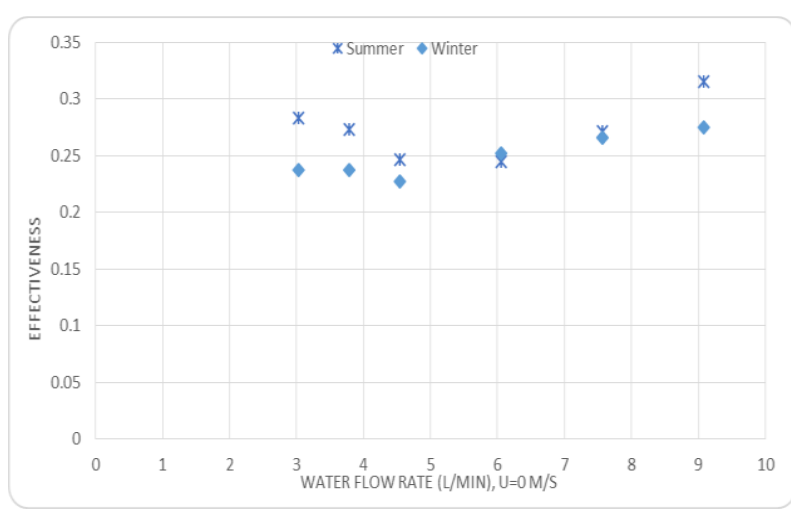

Fig.13 Effectiveness at summer and winter. 


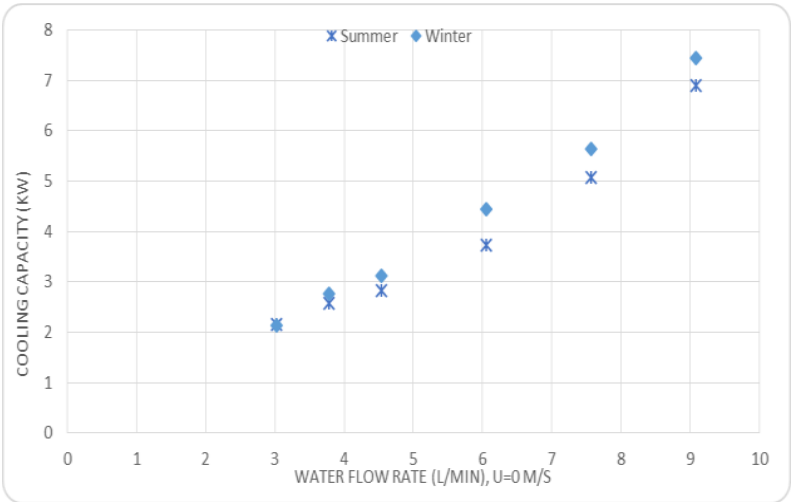

Fig.14 Tower cooling capacity at summer and winter.

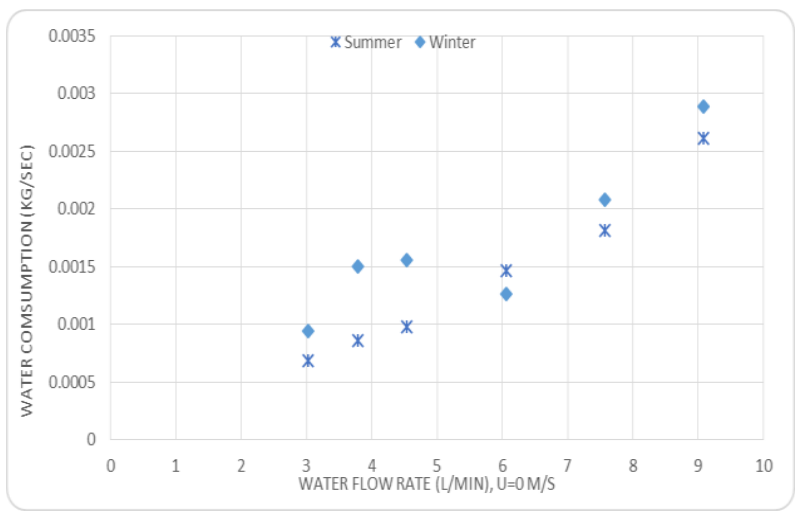

Fig. 15 water consumption at summer and winter.

\section{CONCLUSIONS}

1. Natural draft wet cooling towers can be used at both (cold, wet) and (hot, dry).

2. Relative humidity change, air enthalpy change, and effectiveness are higher at summer than it at winter which can recorded as a feature at summer and that mean high latent heat transfer.

3. Range and cooling capacity are the main feature for tower and they are higher at winter.

4. Heat added to rejected air is more at winter which have more effect at green zone phenomena.

5. The lower value of water to air mass flow rate at winter, the higher total water consumption at winter.

\section{REFERENCES}

[1] Kloppers J. C.and Kroger D. G., Loss Coefficient Correlation for WetCooling Tower Fills, Applied Thermal Engineering, vol.23, pp.2201-221, 2003.

[2] J.C. Kloppers, D.G. Kröger, The Lewis factor and its influence on the performance prediction of wet-cooling towers, International Journal of Thermal Sciences 44 (2005) 879-884.

[3] Kloppers J. C. and Kroger D. G., "Influence of Temperature Inversions on Wet-Cooling Tower Performance", Applied Thermal Engineering, vol.25, pp.1325-1336, 2005.

[4] Bilal A. Qureshi, Syed M. Zubair, A complete model of wet cooling towers with fouling in fills, Applied Thermal Engineering 26 (2006) 19821989

[5] Zhai Z. and Fub S., Improving Cooling Efficiency of Dry-Cooling Towers Under Cross-Wind Conditions by Using Wind-Break Methods Applied Thermal Engineering, vol.26, pp.1008-1017, 2006.

[6] Gao M., Sun F., Wang K., Shi Y. and ZhaoY., Experimental Research of Heat Transfer Performance on Natural Draft Counter Flow Wet Cooling Tower Under Cross-Wind Conditions, International Journal of Thermal Sciences, vol.47, pp. 935-941, 2008.

[7] Lemouari M., Boumaza M., and Kaabi A., "Experimental Analysis of Heat and Mass Transfer Phenomena in a Direct Contact Evaporative Cooling Tower", Journal of Energy Conversion and Management, vol.50, pp.1610-1617, 2009.

[8] Ghassem Heidarinejad, Maryam Karami, Shahram Delfani, "Numerical simulation of counter-flow wet-cooling towers", International Journal of refrigeration, vol.32, pp. $996-1002,2009$

[9] Lemouari M. and Boumaza M., Experimental Investigation of the Performance Characteristics of a Counter Flow Wet Cooling Tower, International Journal of Thermal Sciences, vol.49, pp.2049-2056, 2010.

[10] Rafat Al-Waked, Crosswinds Effect on the Performance of Natural Draft Wet Cooling Towers, International Journal of Thermal Sciences, vol.49, pp.218-224, 2010.

[11] Kai Wang, Feng-zhong Sun, Yuan-bin Zhao, Ming Gao, Lei Ruan, Experimental research of the guiding channels effect on the thermal performance of wet cooling towers subjected to crosswinds - Air guiding effect on cooling tower, Applied Thermal Engineering 30 (2010) 533-538.

[12] Navid Bozorgan and Nariman Bozorgan "Heat and mass transfer evaluation and exergy analysis in the counter flow wet cooling tower of Khuzestan steel company (KSC)", International Journal of Advanced Design and Manufacturing Technology, Vol. 5/ No. 3, 2012.

[13] Xiaoni Qi, Yongqi Liu, and Zhenyan Liu, "Exergy Based Performance Analysis of a Shower Cooling Tower". Journal of Mechanical Engineering vol.59, pp.251-259, 2013.

[14] Williamson, Behnia and S. W. Armfield, Thermal optimization of a natural draft wet cooling tower, International Journal of Energy Research, 2008; 32:1349-1361.

[15] Williamson N., Behnia M. and Armfield S., Comparison of a 2D Axisymmetric CFD Model of a Natural Draft Wet Cooling Tower and a 1D Model, International Journal of Heat and Mass Transfer, vol.51, pp.22272236, 2008.

[16] Alok singh, S P S Rajput. "Application of CFD in Natural Draft Wet Cooling Tower Flow", International Journal of Engineering Research and Applications, ISSN: 2248-9622, Vol. 2, Issue 1, Jan-Feb 2012, pp.10501056.

[17] Z.-G. Zhao, Cooling Tower, China Water-Power Press, Beijing, 2001

[18] Gould Ph. L. and Wilfried B. Krätzig, "Cooling Tower Structures, Structural Engineering Handbook", CRC Press LLC, 1999.

[19] American Society of Heating, Refrigerating, and Air-Conditioning Engineers, ASHRAE System and Equipment Handbook (SI), ch. 36, 2000. 